\title{
Antenatal prevention of atopic dermatitis associated with food allergies
}

\author{
Vera Revyakina*, Elena Berezina, Elena Kuvshiniva, Tatiana Sentsova, Anna Timofeeva, Svetlana Denisova
}

From Food Allergy and Anaphylaxis Meeting 2014

Dublin, Ireland. 9-11 October 2014

To establish effect of probiotic Lactobacillus reuteri which is used in women in the last pregnancy trimester, prevalence of atopic dermatitis in children of the first 6 months of life. One group of women took Lactobacillus reuteri as chewing tablets of probiotic Lactobacillus reuteri, with dairy-limited diet excluding walnuts prior delivery. The second group of pregnant women took only proposed diet. Cumulative prevalence of atopic dermatitis was lower in group of children which mothers took Lactobacillus reuteri (6.7\%) during pregnancy than in group of children of mothers from control group (24.2\%). Analysis of the clinical features of disease showed that in children of the main group was observed mild atopic dermatitis (SCORAD amounted to $12,3+0.14$ points). In children of the control group was middle and severe of atopic dermatitis (SCORAD 22-52 points, respectively).

The use of Lactobacillus reuteri by women in the last pregnancy trimester was positive for general condition and status of gastrointestinal tract. Pregnant women which took Lactobacillus reuteri had increased metabolic activity of lactic flora and recovered balance between aerobic/anaerobic microorganisms. Disorders of intestinal microbial balance in pregnant women in control group were not recovered to the end of pregnancy.

Submit your next manuscript to BioMed Central and take full advantage of:

- Convenient online submission

- Thorough peer review

- No space constraints or color figure charges

- Immediate publication on acceptance

- Inclusion in PubMed, CAS, Scopus and Google Scholar

- Research which is freely available for redistribution 